\title{
Numerical Simulation Based on Heat Transfer Enhancement of Supercritical Fluid in Micro-Fin Tube
}

\author{
Chen Peng-Fei ${ }^{1}$, Chen Kang ${ }^{1,2, *}$, Wang Xiao ${ }^{1}$, and Wen Long ${ }^{1}$ \\ ${ }^{1}$ Institute of solar engineering technology, Northwest Engineering Corporation Limited, Power China, 710065, Xi'an China; \\ ${ }^{2}$ Power China Research Center of Solar Thermal Power Engineering Technology, 710065, Xi'an China
}

\begin{abstract}
With the application of supercritical fluid heat transfer equipment in industrial fields such as solar thermal power generation, chemical industry, aerospace, etc., studying the heat transfer characteristics of supercritical fluid in micro-fin tubes has become a key theoretical basis for the development of micro-fin low-resistance heat transfer enhancement technology. In view of micro-fin tubes with different fin shapes, this paper took into account thermophysical properties of nitrogen under supercritical conditions and completed a numerical simulation study on the heat transfer process of nitrogen in $2 \mathrm{~mm}$ micro-fin tubes under supercritical pressure. The temperature field distribution of supercritical nitrogen in the micro-fin tube was analyzed, and the turbulent flow mechanism of the micro-fin was studied. It was found that micro-fin could increase the heat exchange area, destroy the boundary layer, and improve the heat transfer coefficient. This paper took comprehensive heat transfer performance evaluation factor $P E C$ to compare the influence of different fin shapes on heat transfer enhancement performance of the heat exchange unit. It was found that the comprehensive heat transfer factor of the square straight micro-fin tube was about 1.22 times that of the smooth round tube, and PEC of the triangular straight micro tube was about 1.08 times that of the smooth tube. The results suggest that square straight micro-fin tube has significantly superior heat transfer performance than smooth round tube and triangular straight micro-fin tube.
\end{abstract}

\section{Introduction}

With the rapid development of solar thermal power generation technology, heat exchangers begin to show development trend towards high parameters and compactness. In particular, heat exchange equipment using supercritical fluid as the heat transfer medium represents the research direction of solar thermal power generation heat exchange equipment. At present, microscale spoilers such as micro-fins, metal foams and twisted ribbons can effectively improve heat transfer performance of the heat exchanger, and achieve heat exchanger design goals of high efficiency, compactness and light weight ${ }^{[1-4]}$.

There is a certain geometric similarity between micro-fin tube and inner fin tube in terms of main parameters rib height $e$, helix angle $\alpha$, number of fins $\eta_{f}$, etc., due to its certain similarity in shape with inner fin tube and spiral inner fin tube. Brognaux ${ }^{[5]}$ defined the typical dimension of micro-fin tube: $0.02 \leq e / d_{i} \leq 0.04,1.52 \leq p / e \leq 2.5, \quad 13^{\circ} \leq \alpha \leq 30^{\circ}$. Where, $p=\pi D_{i} / \eta_{f}$. $D_{i}$ is the inner diameter, $\eta_{f}$ is the number of circumferential fins, $p / e$ is dimensionless fin pitch. Jensen $^{[6]}$ defined the dimensionless parameters of microfin tubes with different rib heights based on its different attributes: $e / d_{i} \leq 0.05, \quad \eta_{f}>30$. Webb [7] noticed the difference between the inner micro-fin tube and the inner rough tube. The micro-fin tube can increase the heat exchange area like the inner fin tube, but also has rough wall element similar to the rough wall tube to increase flow separation. At the same time, he also conducted a research on the evaporative heat transfer of R22 in inner micro-fin tube, finding that the heat transfer enhancement coefficient of the inner micro-fin tube was about $110 \%$ higher than that of the smooth round tube, while the drag coefficient only increased by $35 \%$. AlFashed ${ }^{[8]}$ measured the heat transfer and resistance performance of a micro-fin tube with an outer diameter of $15.9 \mathrm{~mm}$, a rib height of $0.3 \mathrm{~mm}$, a helix angle $\alpha$ of $18^{\circ}, \eta_{f}=70$ when $R e=6000 \sim 13000$. The experimental results indicated that the heat transfer coefficient of the micro-fin tube was 1.2 1.8 times that of the smooth tube, and the frictional resistance coefficient was 1.3 1.8 times that of the smooth tube. Using water as working medium, Wang [9] et al. measured the heat transfer coefficient and resistance coefficient of the micro-fin tube in the range of $R e=2500 \sim 40000$, finding that when $R e<6000$, the heat transfer coefficient could be increased by $20 \%$, and there was significant heat transfer enhancement when $R e=6000 \sim 13000$; after $R e>10000$, the micro-fin tube entered a completely rough state, and the drag coefficient no longer changed with the increase of the Reynolds number. At the same time, the heat transfer enhancement of the micro-fin tube was studied

\footnotetext{
* Corresponding author: chen kang@xjtu.edu.cn
} 
under laminar flow, finding that the heat transfer coefficient was not significantly increased compared with that of the smooth round tube. Therefore, it is not recommended to use the micro-fin tube for laminar heat transfer of the fluid. Brognaux ${ }^{[10]}$ studied micro-finned tubes with diameter $14 \sim 47 \mathrm{~mm}, e=0.35 \mathrm{~mm}$, and $e / d_{i}=0.0236$, finding that $N u \approx P r^{n}, 0.55 \leq n \leq 0.57$, with thermal efficiency increased by about $95 \%$, and after $R e>20000$, the drag coefficient was inversely proportional to $R e^{-0.2}$.

FAN Guang-ming and QU Xing-li ${ }^{[11]}$ conducted numerical simulation and experimental research on the single-phase enhanced convective heat transfer in microfin tubes. It was found that increasing rib height could effectively increase the heat transfer area of the fluid and induce rotation of the fluid, thereby reducing the boundary layer thickness. When $R e>40000$, the microfin tube can reach the optimal heat transfer state. At this time, $N u$ is 2.08 times that of a bare tube, and the resistance $f$ is only 1.02 times higher.

In summary, at present, there are only a few experimental results regarding single-phase flow heat transfer of micro-fin tubes, numerical analysis is insufficient, and the mechanism of heat transfer enhancement is not quite clarified. Therefore, it is necessary to analyze the convective heat transfer of supercritical fluid in the micro-fin tube based on the research results of different scholars, understand the heat transfer mechanism of different fin structures in the micro-channel, and use thermal performance evaluation factor $P E C$ to comprehensively analyze the effect of each parameter on heat transfer enhancement and flow pressure loss in the micro-fin tube, thereby providing a basis for the extended application of micro-fin tube in the field of heat transfer enhancement.

\section{Numerical model and method}

\subsection{Physical model}

In this paper, a heat exchange tube with an outer diameter of $2 \mathrm{~mm}$, a wall thickness of $0.05 \mathrm{~mm}$, and a tube length of $100 \mathrm{~mm}$ was selected for numerical simulation (as shown in Figure 1). Where, the cold fluid flows from the inside to the outside along the positive direction of the $Z$ axis.

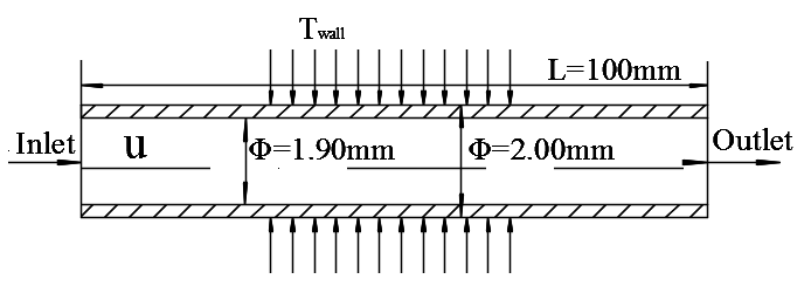

(a) $\mathrm{Z}$ axis

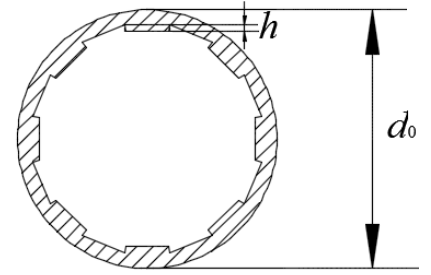

(b) XY axis

Fig. 1. Geometric model of micro-rib tube.

The physical model parameters of the micro-fin tube and the smooth tube adopted in this paper are shown in the following table.

Table 1. Dimensions of different micro-rib tubes.

\begin{tabular}{ccccc}
\hline $\begin{array}{c}\text { Geometrical } \\
\text { dimension }\end{array}$ & $\begin{array}{c}\text { Inner } \\
\text { diameter } \\
d_{i} / \mathrm{mm}\end{array}$ & $\begin{array}{c}\text { Outer } \\
\text { diameter } \\
d_{o} / \mathrm{mm}\end{array}$ & $\begin{array}{c}\text { Rib } \\
\text { height } \\
h / \mathrm{mm}\end{array}$ & $\begin{array}{c}\text { Rib } \\
\text { number } \\
N\end{array}$ \\
\hline $\begin{array}{c}\text { Smooth tube } \\
\text { Square straight } \\
\text { micro-rib tube }\end{array}$ & 1.8 & 2 & 0 & 0 \\
$\begin{array}{c}\text { Square straight } \\
\text { micro-rib tube }\end{array}$ & 1.8 & 2 & 0.05 & 8 \\
$\begin{array}{c}\text { Square straight } \\
\text { micro-rib tube }\end{array}$ & 1.8 & 2 & 0.05 & 16 \\
$\begin{array}{c}\text { Square straight } \\
\text { micro-rib tube }\end{array}$ & 1.8 & 2 & 0.1 & 16 \\
$\begin{array}{c}\text { Square straight } \\
\text { micro-rib tube }\end{array}$ & 1.8 & 2 & 0.2 & 16 \\
$\begin{array}{c}\text { Square straight } \\
\text { micro-rib tube } \\
\text { Triangular }\end{array}$ & 1.8 & 2 & 0.4 & 16 \\
straight micro- \\
rib tube
\end{tabular}

\subsection{Governing equation}

The governing equation is composed of threedimensional steady-state incompressible continuity equation, Reynolds average Navier-Stokes equation and energy equation.

Continuity equation:

$$
\nabla \cdot(\rho u)=0
$$

Where, $\rho$ is the fluid density, and $u$ is fluid velocity. Momentum conservation equation:

$$
\frac{\partial}{\partial x_{j}}\left(\rho u_{i} u_{j}\right)=-\frac{\partial p}{\partial x_{i}}+\frac{\partial}{\partial x_{i}}\left[\left(\mu+\mu_{t}\right)\right]
$$

Energy equation:

$$
\begin{aligned}
& \frac{\partial}{\partial x_{j}}\left(\rho u_{i} e_{t}\right)+\frac{1}{r} \frac{\partial}{\partial r}\left(r \rho u_{r} e_{t}\right)= \\
& \frac{\partial}{\partial x}\left[\lambda_{\text {eff }} \frac{\partial T}{\partial x}\right]+\frac{1}{r} \frac{\partial}{\partial r}\left[r \lambda_{\text {eff }} \frac{\partial T}{\partial r}\right]
\end{aligned}
$$

Where, $e_{t}$ is the internal fluid energy, and $\lambda_{\text {eff }}$ is the effective thermal conductivity. 


\subsection{Boundary conditions}

The nitrogen inlet velocity in the tube is $4 \mathrm{~m} \cdot \mathrm{s}^{-1}$, the inlet pressure is $100 \mathrm{bar}$, the inlet temperature is $188 \mathrm{~K}$, the constant wall temperature boundary condition is set to $300 \mathrm{~K}$, the outlet is the pressure outlet, there is no slip boundary condition, and the buoyancy effect is ignored. Taking into account the actual heat transfer, the boundary conditions herein are hypothesized as follows:

1) The flow of fluid in the tube is single-phase heat transfer without phase change;

2) Real gas is inside the tube, and NIST physical property model is used to calculate the physical property parameters of $\mathrm{N} 2$;

3) Gravity effect is not considered;

4) The fluid is in a convective heat transfer condition with fully developed turbulent flow.

The equivalent diameter in the paper is defined as:

$$
D_{h}=\frac{4 A}{P}
$$

Where, $A$ is the cross-sectional area of circulation $/ \mathrm{m}^{2}$; $P$ is the wet circumference $/ \mathrm{m}$.

The average heat transfer coefficient $h_{m}$ and average Nusselt number $N u_{m}$ in the micro-fin tube channel are defined as follows:

$$
\begin{aligned}
& h_{m}=\frac{q}{\left(T_{w}-T_{f}\right) A} \\
& N u_{m}=\frac{h_{m} D_{h}}{\lambda}
\end{aligned}
$$

Where, $q$ is the heat flux density of the entire wall $/ \mathrm{w} \cdot \mathrm{m}^{-2}, T_{w}$ is the wall temperature $/ \mathrm{K}, T_{f}$ is the average temperature of the fluid/K, $D_{h}$ is the hydraulic diameter $/ \mathrm{m}$, and $\lambda$ is the fluid thermal conductivity/ $\mathrm{W} \cdot \mathrm{m}^{-1} \cdot \mathrm{K}^{-1}$.

The comprehensive heat transfer enhancement evaluation factor $P E C$ proposed by Webb-Bergles [12] has a simple definition and clear physical meaning, which has been widely used.

$$
P E C=\frac{N u / N u_{0}}{\sqrt[3]{f / f_{0}}}
$$

Where, $N u$ is the Nusselt number of the micro-fin tube, $N u_{0}$ is the Nusselt number of the smooth tube, $f$ is the resistance coefficient of the micro-fin tube, and $f_{0}$ is the resistance coefficient of the smooth tube.

To compare fluid flow resistance of different models, this paper adopts friction coefficient as the comparison standard. The formula in this paper for calculating friction coefficient $f$ is as follows:

$$
f=\frac{2 \Delta p D_{h}}{\rho u^{2} L}
$$

Where, $\Delta p$ is the average pressure drop/ $\mathrm{Pa}$ in the micro-fin tube calculation area.

\section{Experimental results and discussion}

Since the boundary condition of constant wall temperature is adopted and the tube length is $100 \mathrm{~mm}$, the entire heat exchange tube is selected as the research object in this paper. Figure 2 shows distribution of the average fluid temperature evolution with distance along the axis under uniform wall temperature. The average temperature is calculated by the following relational expression:

$$
T_{f}=\frac{\int_{A_{c}} c_{p} \rho T d A}{\int_{A_{c}} c_{p} \rho d A}
$$

Where, $T_{f}$ is the average fluid temperature $/ \mathrm{K}, A$ is the heat transfer area $/ \mathrm{m}^{2}, c_{p}$ is the specific heat capacity at constant pressure $/ \mathrm{J} \cdot \mathrm{kg}^{-1} \cdot \mathrm{K}^{-1}, \rho$ is the fluid density $/ \mathrm{kg} \cdot \mathrm{m}^{-3}$, and $T$ is the fluid temperature/ $\mathrm{K}$.

During the heating process of $100 \mathrm{~mm}$ tube, smooth tube and triangular straight micro-fin tube have smaller average temperature rise than square straight micro-fin tube.

Table 2 The logarithmic mean temperature difference between inlet and outlet under different fin shapes

\begin{tabular}{cccc}
\hline & $\begin{array}{c}\text { Smooth } \\
\text { tube }\end{array}$ & triangle & $\begin{array}{c}\text { straight fin } \\
\text { tube }\end{array}$ \\
\hline$T_{\text {in }} / \mathrm{K}$ & 188 & 188 & 188 \\
$T_{\text {out }} / \mathrm{K}$ & 227.37 & 229.04 & 245.86 \\
$\Delta T / \mathrm{K}$ & 90.90 & 89.92 & 79.60 \\
& & & \\
Compared with & 0 & 1.07 & 12.43 \\
smooth tube $\%$ & & & \\
\hline
\end{tabular}

In Figure 2, average temperature changes greatly under different fin shapes. Where, the average temperature change curve of the triangular straight micro-fin tube almost overlaps with that of smooth round tube, but it is significantly lower than the temperature change curve of the square straight micro-fin tube. Where, at the exit section, the square straight micro-fin tube has very obvious temperature rise, with the average temperature $46.98 \%$ higher than that of the smooth tube, while that of triangular straight micro-fin tube is only $4.25 \%$ higher compared to smooth tube. It suggests that under the same boundary conditions, the heat transfer effects of the three types of round tubes are ranked as that of square straight micro-rib tube, followed by that of triangular straight micro-rib tube, while smooth tube has the worst heat transfer effect. 


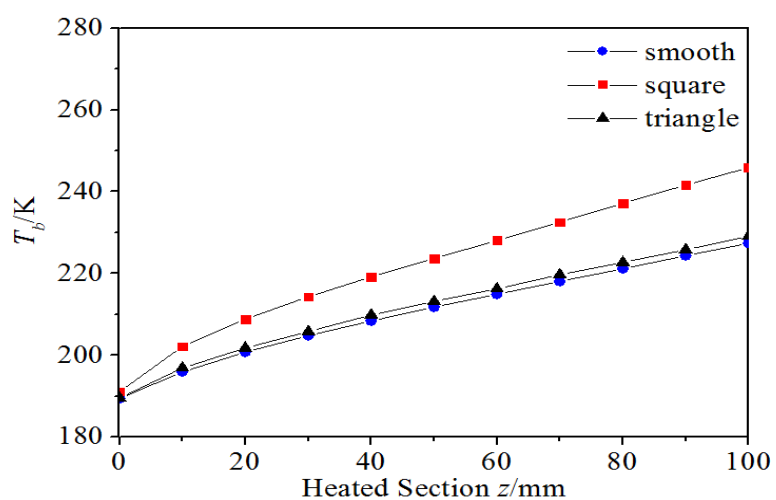

Fig. 2. Distribution of average temperature along the axial direction under different fin shapes

Figure 3 shows the change curve of the axis temperature along the tube. It can be seen that there is significant temperature increase at the axis due to the presence of micro-fins. Where, the triangular straight micro-fin tube presents consistent change trend with the round tube, while straight micro-fin tubes have a very significant elevation compared with the two. In particular, after $40 \mathrm{~mm}$ on the axis, the temperature gradient along the axis has a significant increase at 50 $\mathrm{mm}$, with that of square straight micro-fin tube about $15 \sim 20 \mathrm{~K}$ higher compared to the triangular straight micro-fin tube. Consistent with the change trend of the average temperature, the temperature rise is very obvious at the axis of the square straight micro-fin tube, while the temperature change of triangular micro-fin tube and smooth tube is basically the same, exhibiting no obvious change.

From the above temperature distribution diagram along the axis, it can be clearly seen that temperature distribution of the micro-finned tube exhibits significant change compared to smooth round tube.

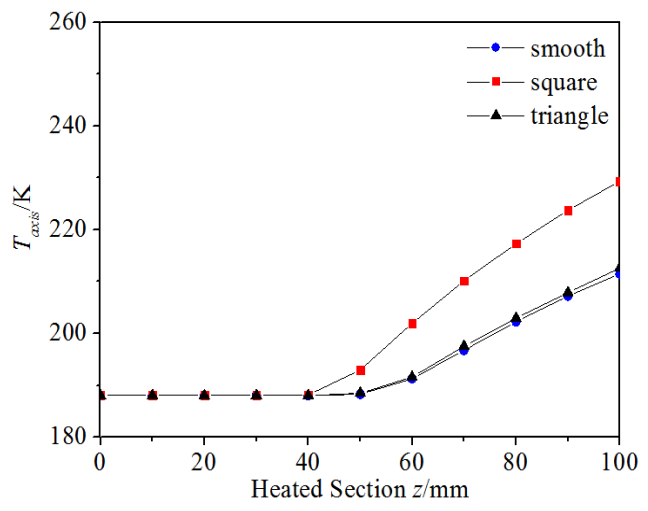

Fig. 3. Temperature distribution along the axis under different fin shapes

Figure 4 shows the temperature profile at $z=60 \mathrm{~mm}$ cross-section under different fin shapes. It can be seen that with the change of the radius $r$, the temperature gradient in the radial direction is continuously reduced; the square straight micro-fin tube has higher temperature field strength at the cross section than triangular straight micro-fin tube and smooth round tube. That is, under the same radial height, the square straight micro-fin tube has much higher temperature than the triangular straight micro-fin tube and the smooth round tube. In particular, the temperature of the fluid between the ribs is much higher than that of the surrounding fluid. As a result, the average temperature at the entire section is nearly $20 \mathrm{~K}$ higher.

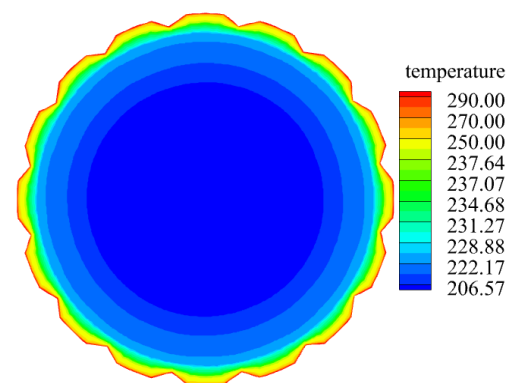

(a) Triangular rib

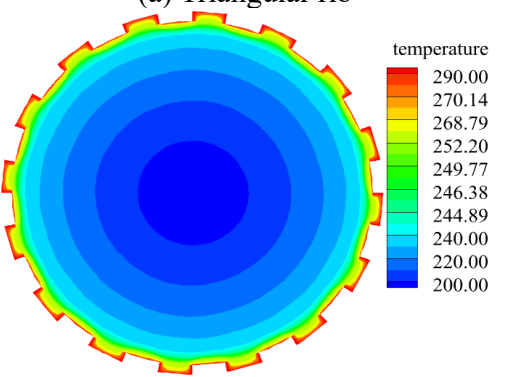

(b) Square rib

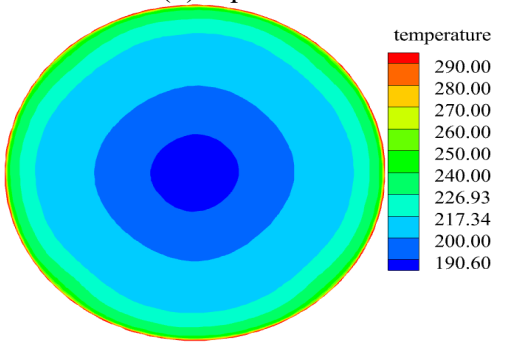

(c) Smooth round tube

Figure 4 Temperature cloud diagram at $\mathrm{z}=60 \mathrm{~mm}$ cross-section under different fin shapes

In this paper, $P E C$ is used to indicate the comprehensive heat transfer enhancement factor, and the corresponding parameters can be obtained by calculation to describe heat transfer of various tube types. The specific calculation results are as follows:

Table 3 The logarithmic mean temperature difference between inlet and outlet under different fin shapes

\begin{tabular}{cccc}
\hline & $\begin{array}{c}\text { Smooth } \\
\text { tube }\end{array}$ & triangle & $\begin{array}{c}\text { straight } \\
\text { fin tube }\end{array}$ \\
\hline$N u$ & 160.13 & 244.60 & 162.71 \\
$f$ & 0.03 & 0.04 & 0.04 \\
$P E C$ & 1.00 & 1.28 & 1.08 \\
\hline
\end{tabular}

It can be seen from the above table that $N u$ is significantly higher in square straight micro-rib tube than in the smooth tube and the triangular straight micro-rib tube, and $N u$ is increased by about $52.81 \%$; the friction factor of the square straight micro-rib tube is 1.33 times that of the smooth tube, but with small difference between the triangular straight micro-rib tube and the smooth tube. Regarding the comprehensive evaluation factor, $P E C$ of the square straight micro-rib tube is 1.28 times that of the smooth tube, and $P E C$ of the triangular 
straight micro-rib tube is about 1.08 times that of the smooth tube. It can be seen that the introduction of straight micro-fins enhances the heat transfer performance of supercritical nitrogen in the tube.

\section{Conclusion}

This chapter discussed the effect of different fin shapes on the heat transfer process in low-temperature nitrogen tubes under supercritical pressure, and conducted detailed numerical simulation studies to analyze the temperature field distribution of supercritical nitrogen in micro-fin tubes. The comprehensive heat exchange performance evaluation factor $P E C$ was used to evaluate the heat transfer enhancement.

The introduction of micro-fins in the tube can change the velocity field of the supercritical fluid, which makes the fluid flow in the tube oscillate, and increases the turbulence $I$, resulting in the enhancement of heat transfer capacity. The introduced fin reduces the flow velocity of the inter-costal fluid and thickens the boundary layer. Excessive boundary layer thickness will increase thermal resistance in the heat transfer process, affect the convective heat transfer effect between the wall and the fluid. Comprehensive heat transfer performance evaluation factor $P E C$ was taken to evaluate heat transfer performance of different heat exchange tubes. The comprehensive heat transfer factor of square straight micro-fin tube was about 1.22 times that of the smooth round tube, and PEC of the triangular straight micro-fin tube was about 1.08 times that of the smooth tube. The results suggest that straight micro-fin tube has significantly superior heat transfer performance than smooth round tubes and triangular straight microrib tubes.

\section{Acknowledgement}

This work was supported by Natural Science Basic Research Program of Shaanxi (Grant No.2020JQ-1001).

\section{References}

1. Chen K, Guo L, Xie X, et al. Experimental investigation on enhanced thermal performance of staggered tube bundles wrapped with metallic foam $[\mathrm{J}]$. International Journal of Heat \& Mass Transfer, 2018, 122: 459-468.

2. Chen K, Guo L, Wang H. A review on thermal application of metal foam [J]. Science China Technological Sciences, 2020, https://doi.org/10.1007/s11431-020-1637-3

3. CHEN Kang, CHEN Peng-fei, LI Wen-sheng, et al. Permeation flow characteristics in electrodeposited metal foams[J]. Journal of Xi'an Jiaotong University, 2020, 54(5): 87-94

4. CHEN Kang, GUO Liejin, ZHAO Liang, et al. Experimental Investigation on Fluid Flow and HeatTransfer Properties of Metallic Foam Tube-Bundle
[J]. Journal of Engineering Thermophysics, 2016, 37(4): 770-774.14(4):601-617.

5. Brognaux LJ, Webb RL, Chamra LM, et al. Singlephase heat transfer in micro-fin tubes[J]. International Journal of Heat and Mass Transfer. 1997, 40(18): 4345-4357.

6. Jensen M K, Vlakancic A. Technical Note Experimental investigation of turbulent heat transfer and fluid flow in internally finned tubes[J]. International Journal of Heat \& Mass Transfer, 1999, 42(7):1343-1351.

7. Webb R L, Eckert E R G, Goldstein R J. Heat transfer and friction in tubes with repeated-rib roughness[J]. International Journal of Heat \& Mass Transfer, 1971, 14(4):601-617.

8. Al-Fahed S, Chamra L M, Chakroun W. Pressure drop and heat transfer comparison for both microfin tube and twisted-tape inserts in laminar flow $[\mathrm{J}]$. Experimental Thermal \& Fluid Science, 1998, 18(4):323-333.

9. Wang C C, Chiou C B, Lu D C. Single-phase heat transfer and flow friction correlations for microfin tubes $[\mathrm{J}]$. International Journal of Heat \& Fluid Flow, 1996, 17(5):500-508.

10. Brognaux L J, Webb R L, Chamra L M, et al. Single-phase heat transfer in micro-fin tubes[J]. International Journal of Heat \& Mass Transfer, 1997, 40(18):4345-4357.

11. QU Xing-li, YAN Chang-qi, FAN Guang-ming. Numerical simulation on single-phase flow and heat transfer in micro-fin tubes [J]. Applied Science and Technology, 2009, 36(4): 65-68. 